\title{
Avaliação da reatividade potencial de rochas utilizadas como agregados na construção civil no estado do Rio Grande do Sul
}

\author{
Assesment of the potential reactivity of \\ rocks used as aggregates in civil \\ construction in the Rio Grande \\ do Sul state
}

\author{
Fernanda Macedo Pereira ${ }^{1}$, Paulo César Pereira das Neves ${ }^{1}$, \\ Denise Maria Lenz ${ }^{1}$, José Carlos Krause de Verney ${ }^{1}$
}

\footnotetext{
${ }^{1}$ Programa de Pós-Graduação em Engenharia de Materiais e Processos Sustentáveis - PGEMPS/ULBRA, Canoas, RS, Brasil. e-mail: engcivil.canoas@ulbra.br, nevespc@yahoo.com.br, denise.lenz@gmail.com,jcverney@ulbra.br
}

\section{RESUMO}

A reação álcali-agregado (RAA) é uma das possíveis causas de redução da durabilidade e deterioração das estruturas de concreto, sendo motivo de preocupação à integridade e segurança das construções em âmbito internacional. Casos confirmados no Brasil, nos últimos anos, afetaram estruturas como fundações de edificações residenciais, pontes, barragens, entre outras. O processo da RAA se desenvolve a partir da combinação de agentes como os álcalis presentes no cimento Portland e agregados reativos, com a presença constante de umidade, e como resultado forma-se um gel higroscópico no entorno do agregado, causando expansão, fissuração do concreto, com possível exsudação do gel, sendo estes danos irreversíveis. O presente trabalho tem por objetivo apresentar uma caracterização petrográfica de quatro rochas utilizadas na construção civil no estado do Rio Grande do Sul, bem como verificar a reatividade potencial das rochas pelo método acelerado das barras. Dois agregados foram identificados como rochas vulcânicas e os outros dois foram identificados como de origem ígnea subvulcânica e ígnea plutônica, respectivamente. Enquanto as rochas vulcânicas mostraram um efeito deletério na reatividade potencial, as outras duas mostraram comportamento inócuo, com potencial de utilização como agregados em obras civis, sem a necessidade de adição de materiais mitigatórios, visto o nível de expansão estar de acordo com critérios estabelecidos nas normas brasileiras.

Palavras-chave: agregados, reação álcali-agregado, concreto, caracterização petrográfica.

\begin{abstract}
The alkali-aggregate reaction (AAR) is one of the possible causes for reduction of the durability and deterioration of concrete structures, being a matter of integrity and safety concern in concrete structures worldwide. In recent years cases confirmed in Brazil have affected structures such as foundations of residential buildings, bridges, dams, among others. The AAR process develops from the combination of agents such as alkalis present in Portland cement and reactive aggregates, with the constant presence of moisture, and as a result a hygroscopic gel is developed around the aggregate, resulting in expansion and cracking of the concrete, with possible bleeding of the gel, turning into irreversible damages. The present study aims to present a petrographical characterization of four types of rocks used in civil construction in the state of Rio Grande do Sul, as well as to verify the potential reactivity of these rocks by the accelerated bar method. Two aggregates were identified as volcanic rocks and the other two were identified as being sub-volcanic igneous and plutonic igneous origin, respectively. While volcanic rocks showed a deleterious effect in alkali-aggregate reactivity, the other two rocks showed innocuous behavior, with potential to be used as aggregates in civil works, without being necessary any addition of mitigating materials, since their expansion levels are in compliance with the criteria established in the Brazilian standards.
\end{abstract}


Keywords: aggregates, alkali-aggregate reaction, concrete, petrographical characterization.

\section{INTRODUÇÃO}

Entre as possíveis causas da redução da durabilidade e deterioração das estruturas de concreto, a reação álcali-agregado (RAA) tem sido motivo de preocupações ao meio técnico nacional. A RAA, resumidamente, consiste em reações químicas que ocorrem entre agregados reativos (minerais silicosos reativos) e os hidróxidos alcalinos dissolvidos na solução dos poros do concreto [1], gerados na fase de hidratação do cimento Portland. Como resultado da reação álcali-agregado forma-se um gel higroscópico expansivo, podendo gerar expansão, fissuração, exsudação de gel e pipocamentos (pop-out) no concreto, com redução de resistência e módulo de deformação, além de movimentações diferenciais nas estruturas.

A velocidade de desenvolvimento e a magnitude dos danos causados pela reação álcali-agregado dependem de uma série de fatores, como o teor de álcalis do cimento, a água de amassamento, a natureza e quantidade disponível de agregados reativos, a temperatura ambiente, a umidade disponível e eventuais restrições. Para a ocorrência de expansões, os agregados precisam conter sílica reativa, sendo que existe um teor da mesma no agregado, que leva à expansão máxima, correspondendo a um pico definido como conteúdo péssimo [2,3].

CARLES-GIBERGUES e HORNAIN [4] destacam que as diferentes espécies reativas reagem com velocidades variáveis e que a expansão decorrente da RAA depende da natureza do agregado e da sua dosagem no interior do concreto.

As obras hidráulicas, por reunirem as condições que favorecem o aparecimento da reação, como grandes volumes de concreto e condições de umidade necessárias, constituem o tipo de estrutura de concreto com maior probabilidade de desenvolvimento desse tipo de manifestação patológica [5], muito embora o fenômeno possa se manifestar em qualquer tipo de estrutura, desde que haja presença de minerais reativos, alcalinidade e umidade no concreto. Diversos fatores concorrem para que haja o desencadeamento desta reação, entre os quais merecem destaque a influência da cristalinidade e o grau de deformação do quartzo em agregados provenientes de rochas plutônicas, além do grau de mesóstase dos agregados que provém de rochas vulcânicas.

Segundo SILVA [6], no Brasil, o interesse na reação álcali-agregado em estruturas de concreto aumentou significativamente nas últimas décadas, em função do surgimento de novos casos da manifestação, do risco relacionado à segurança e dos elevados custos e dificuldades de reparos e recuperação.

TIECHER e DAL MOLIN [7], bem como VALDUGA et al. [8] apontam o maior número de casos de reação álcali-agregado em estruturas de médio e pequeno porte como fundações de edificações residenciais, pontes, cambotas de túneis, entre outras, incentivando cada vez mais a avaliação dos agregados disponíveis e utilizados na construção civil no país. Diversos pesquisadores têm tratado o problema no que se refere à potencialidade reativa dos agregados $[9,10,11,12,13]$ e, também, no que se refere à interferência de adições minerais nas reações $[14,15,16,17,21]$.

RAJABIPOUR et al. [18] enfatizam que conhecer o comportamento dos agregados e as principais fases reativas do concreto é fundamental para melhorar o entendimento dos mecanismos da reação álcaliagregado, bem como identificar a melhor maneira de mitigar tal reação.

Segundo TIECHER et al. [12], mesmo os agregados oriundos de rochas básicas, com baixo teor de sílica, como os basaltos, têm apresentado elevada reatividade em ensaios acelerados de avaliação de reatividade. Os autores explicam que tal reatividade é normalmente atribuída ao material amorfo (vidro vulcânico) presente nos interstícios dos grãos, mas salientam que as fases álcali-reativas dos basaltos e rochas vulcânicas podem ser, além do vidro vulcânico, fases microcristalinas que representam o resíduo rico em álcalis e sílica e que constituem a mesóstase intergranular.

O presente artigo objetiva caracterizar petrograficamente quatro agregados naturais utilizados na construção civil no estado do Rio Grande do Sul, Brasil, visando verificar a ocorrência de quartzo deformado e o grau de cristalinidade em rochas intrusivas e obsidiana (vidro vulcânico), além da incipiente presença de processos mesostáticos nas rochas efusivas. Também foram avaliados ensaios de reatividade álcali-agregado, realizados com estas litologias, através da determinação da expansão em barras de argamassa pelo método acelerado, visando corroborar os dados obtidos pelas análises petrográficas. 


\section{MATERIAIS E MÉTODOS}

\subsection{Materiais}

Para o presente trabalho foram utilizados quatro litótipos, provenientes do estado do Rio Grande do Sul, comumente utilizados como agregados na indústria da construção civil, e identificados como agregados I e II (rochas vulcânicas) e III e IV (rochas plutônicas). A Tabela 1 apresenta a massa específica das rochas analisadas, determinada segundo a NBR NM 53 [22].

Tabela 1: Massa específica das rochas.

\begin{tabular}{c|c}
\hline ROCHA & MASSA ESPECÍFICA $\mathbf{( k g / \mathbf { d m } ^ { 3 } )}$ \\
\hline I & 2,94 \\
\hline II & 2,82 \\
\hline III & 3,10 \\
\hline IV & 2,80 \\
\hline
\end{tabular}

As rochas vulcânicas analisadas pertencem à Formação Serra Geral (Província Paraná), e correspondem aos basaltos toleíticos do vulcanismo básico que atingiu o sul do Brasil durante a Era Mesozóica. A rocha subvulcânica (olivina-gabro) pertence à Província Paraná, relacionada ao magmatismo Serra Geral. A rocha plutônica pertence à Província Mantiqueira e representa o magmatismo arqueano ocorrido no estado do Rio Grande do Sul, Brasil [19].

As quatro amostras foram coletadas, respectivamente, em pedreiras dos seguintes locais: agregado I Montenegro (29 ${ }^{\circ} 50^{\prime} 52$ "S, $51^{\circ}$ 29'15" W), agregado II - Campo Bom (29 38 '46 "S; 51 0 04'37 "W), agregado 3 - Gravataí (29 50'52" S, $\left.51^{\circ} 067^{\prime} 57^{\prime W}\right)$ e agregado 4 - Porto Alegre (30 05'11" S, $\left.51^{\circ} 09^{\prime} 05^{\circ} \mathrm{W}\right)$.

Nos ensaios de reatividade álcali-agregado, para a produção das argamassas com cada agregado analisado, foi utilizado cimento Portland do tipo CP V-ARI, segundo a NBR 5733 [28]. A amostra utilizada apre-

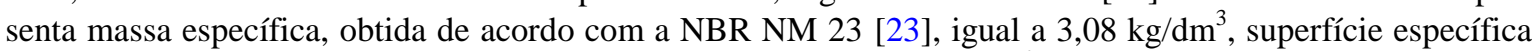
Blaine, determinada de acordo com a NBR NM 76 [24], igual a $4690 \mathrm{~cm}^{2} / \mathrm{g}$ e, segundo informações do fabricante, resíduo insolúvel igual a $1,0 \%$ e $\mathrm{Na}_{2} \mathrm{Oeq}$ (equivalente alcalino) igual a 1,0\%.

\subsection{Métodos}

Para a análise dos agregados, primeiramente, em fratura fresca, procedeu-se a análise macroscópica dos mesmos. Após, a composição mineralógica e os aspectos texturais das rochas analisadas foram obtidos através de análise petrográfica em microscopia óptica de luz transmitida, em microscópio binocular Olympus. As fases minerais e o material intersticial (mesóstase) foram determinadas pela quantificação modal (vol\%) em lâminas delgadas com $30 \mu \mathrm{m}$ de espessura, além de documentação fotomicrográfica. A metodologia utilizada consta na NBR 15845 [25] e a classificação petrográfica seguiu as recomendações de Le Maitre [20]. Para a análise da composição do plagioclásio foi utilizado o método Michel-Lèvy (extinção paralela segundo (010)). Os minerais opacos foram caracterizados com análise de seção polida, com microscopia de luz refletida.

A avaliação da reatividade álcali-agregado dos quatro litótipos analisados foi realizada através da verificação da expansão em barras de argamassa, moldadas com os agregados obtidos dos referidos litótipos, com base nas recomendações do método acelerado referenciado na NBR 15577-4 [27]. Segundo este método três corpos de prova com dimensões de $(25$ x 25 x 285) mm (Figura 1 a) são moldados para verificação da expansão. Cada amostra de agregado foi cominuída em britador de mandíbulas, lavada e preparada nas frações passantes nas peneiras $4,75 \mathrm{~mm}, 2,36 \mathrm{~mm}, 1,18 \mathrm{~mm}, 600 \mu \mathrm{m}$ e $300 \mu \mathrm{m}$. As argamassas foram produzidas com traço 1:2,25 (440 g de cimento Portland e $990 \mathrm{~g}$ de agregado) e relação água/cimento igual a 0,47. Decorridas $24 \mathrm{~h}$ da moldagem, os corpos de prova foram desmoldados e colocados imersos em água a $80^{\circ} \mathrm{C}$, por $24 \mathrm{~h}$, sendo posteriormente imersos em solução de $\mathrm{NaOH}\left(1 \mathrm{~N} \mathrm{a} 80^{\circ} \mathrm{C}\right)$, por 30 dias. Neste período são realizadas oito medidas de expansão, com relógio comparador (Figura 1b). O limite de expansão para classificação do agregado como potencialmente reativo $(\geq 0,19 \%)$ ou potencialmente inócuo $(<0,19 \%)$ seguiu a recomendação da NBR 15577-1 [26]. 

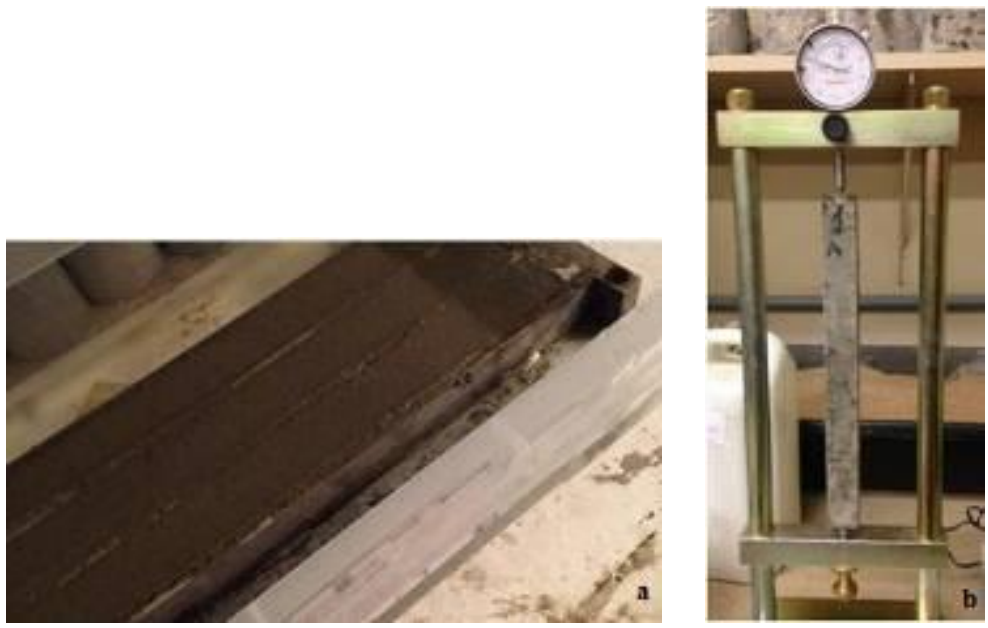

Figura 1: a) Moldagem dos corpos de prova de argamassa; b) Leitura da expansão com auxílio de relógio comparador.

\section{RESULTADOS}

Os litótipos analisados apresentaram as características apresentadas a seguir.

\subsection{Análise petrográfica da Rocha I - procedência Montenegro/RS/Brasil}

a) Descrição macroscópica: rocha de granulação fina, de coloração cinza escuro em estado seco. Em estado úmido não apresentou variação. Estrutura maciça sem orientação mineral.

b) Descrição microscópica: a principal textura é a porfirítica, caracterizada pela presença de fenocristais de plagioclásio e clinopiroxênio, com dimensões variáveis entre 0,2 a $0,4 \mathrm{~mm}$, imersos em matriz intergranular hipidiomórfica fina $(<0,1 \mathrm{~mm})$, definida pela presença dominante de cristais prismáticos e ripiformes de plagioclásio, com espaços intersticiais ocupados por diminutos cristais de clinopiroxênio e opacos octaédricos (magnetita), com tamanhos inferiores a $0,1 \mathrm{~mm}$ e áreas mais restritas compostas por matriz vítrea. Apresenta, ainda, vesículas ameboides entre 0,1 a $0,3 \mathrm{~mm}$, muitas preenchidas por uma massa verde muito fina de cristais de celadonita e outras por agregados de calcita. Caracteriza-se por uma rocha tipicamente de natureza vulcânica, com análise modal (vol\%) acusando 60-65\% de plagioclásio (campo da andesinalabradorita), 15-20\% de augita, 12-15\% de matriz vítrea, 1\% de opacos (magnetita), 2-3\% de vesículas. Não foram evidenciados efeitos intempéricos e a mesma não apresenta microdescontinuidades. Pelos parâmetros de Le Maitre [20] a rocha corresponde petrograficamente a um basalto. (Figuras 2a e 2b).
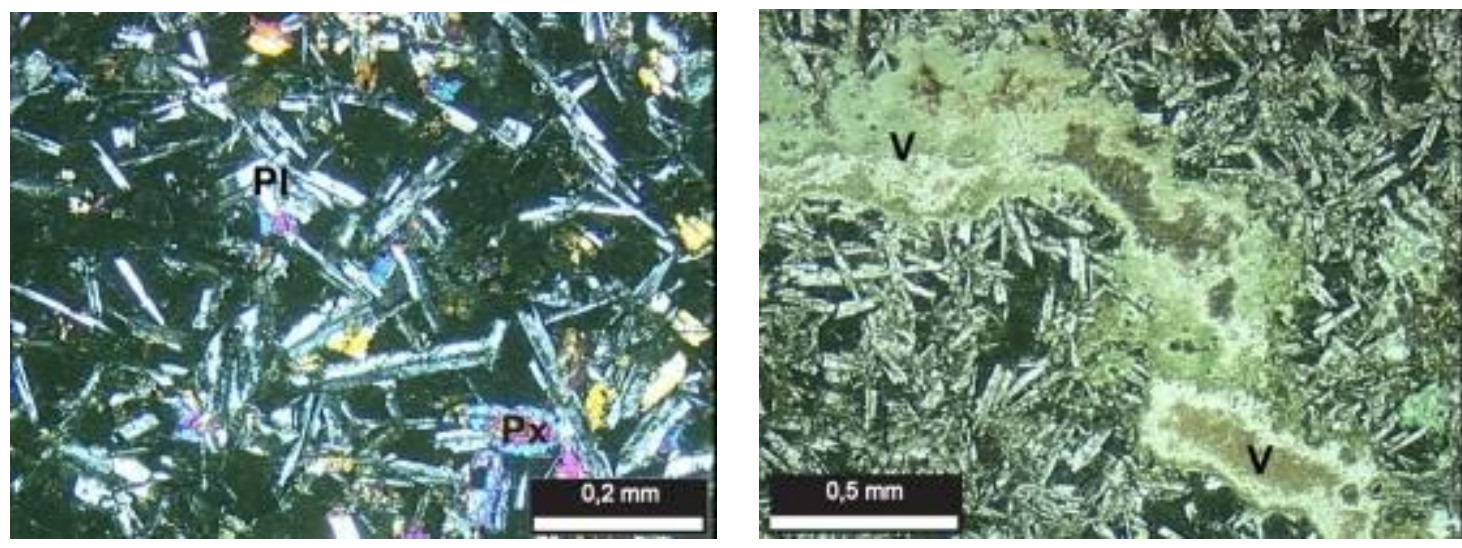

Figura 2: Rocha I: basalto a) fenocristais de plagioclásio (PI) e augita (Px) imersos em matriz intergranular composta por plagioclásio, magnetita e vidro vulcânico (LP com nicóis cruzados) e b) vesículas amebóides (V) preenchidas por celadonita (verde) e zonação de calcita (branco) (LP com nicóis descruzados).

\subsection{Análise petrográfica da Rocha II - procedência Campo Bom/RS/Brasil}

a) Descrição macroscópica: rocha de granulação fina de coloração cinza escuro, em estado seco. Em estado úmido não apresentou variação. Estrutura maciça sem orientação mineral. 
b) Descrição microscópica: a principal textura é porfirítica, caracterizada pela presença de fenocristais de plagioclásio e clinopiroxênio, prismáticos e euédricos, com dimensões variáveis entre 1 a $2 \mathrm{~mm}$, imersos em matriz intergranular hipidiomórfica fina (grãos entre 0,1 e $0,4 \mathrm{~mm}$ ), definida pela presença dominante de cristais prismáticos e ripiformes de plagioclásio, com espaços intersticiais ocupados por diminutos cristais de clinopiroxênio e magnetita, com tamanhos próximos a $0,1 \mathrm{~mm}$ e áreas mais restritas compostas por matriz muito fina. Esta matriz corresponde a uma textura micrográfica ou microgranofírica, composta por um resíduo final de cristalização à base de feldspato potássico e quartzo. Caracteriza-se por uma rocha tipicamente de natureza vulcânica, com análise modal (vol\%) acusando 70-75\% de plagioclásio (campo da andesinalabradorita), $12-15 \%$ de augita, 2-3\% de opacos (magnetita), 5-7\% de matriz muito fina e 2-3\% de vesículas. Foram evidenciados efeitos intempéricos, com incipiente argilização do plagioclásio e oxidação da magnetita. Não há indícios de microdescontinuidades. Pelos parâmetros de Le Maitre [20] a rocha corresponde petrograficamente a um basalto (Figura 3).

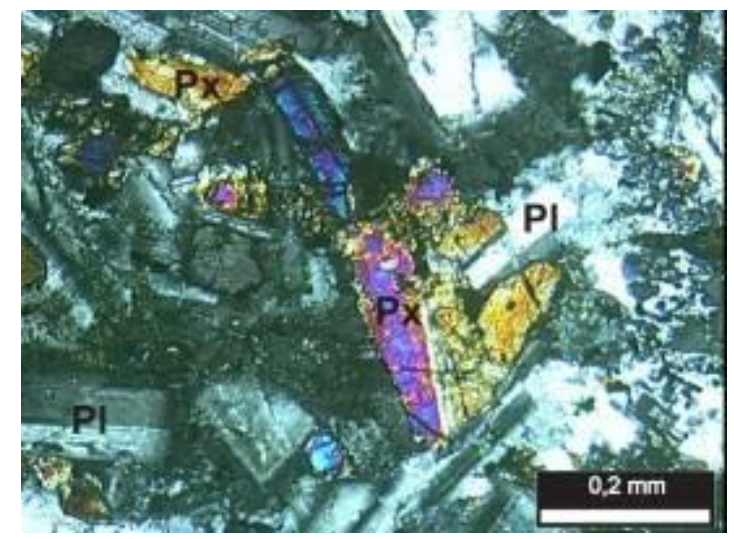

Figura 3: Rocha II: basalto - fenocristal de clinopiroxênio (augita - Px) no centro da fotomicrografia, com macla lamelar. À direita, após cristal de plagioclásio (Pl), matriz fina (quartzo + feldspato potássico, em textura micrográfica).

\subsection{Análise petrográfica da Rocha III - procedência Gravataí/RS/Brasil}

a) Descrição macroscópica: rocha de granulação equigranular média, de coloração cinza-escuro. Em estado úmido não apresentou variação. Estrutura maciça sem orientação mineral.

b) Descrição microscópica: a principal textura é a inequigranular hipidiomórfica média, caracterizada por cristais prismáticos de plagioclásio e clinopiroxênio e subordinariamente cristais globulares de olivina. Caracteriza-se por uma rocha tipicamente de natureza ígnea subvulcânica, com análise modal (vol\%) acusando 50-55\% de plagioclásio (campo da andesina-labradorita), 25-30\% de augita, 10-15\% de olivina, 2-3\% de opacos e clorita. Foram evidenciados efeitos intempéricos, com incipiente argilização do plagioclásio e oxidação da magnetita. Não há indícios de microdescontinuidades, nem de alteração intempérica. Ocorre substituição de olivina por clorita de natureza hidrotermal. Pelos parâmetros de Le Maitre [20] a rocha corresponde petrograficamente a um olivina-gabro (Figura 4).

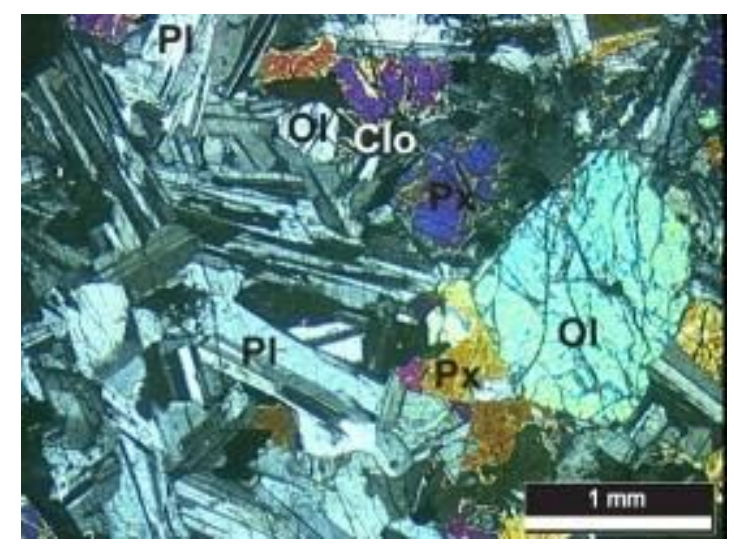

Figura 4: Rocha III: olivina-gabro - textura inequigranular hipidiomórfica, com cristais de plagioclásio (Pl), augita (Px) e olivina (Ol) e clorita hidrotermal (Clo). 


\subsection{Análise petrográfica da Rocha IV - procedência Porto Alegre/RS/Brasil}

a) Descrição macroscópica: rocha equigranular média, coloração cinza-claro, com pontuações pretas. Em estado úmido não apresentou variação. Estrutura mostrando incipiente foliação.

b) Descrição microscópica: a principal textura é a inequigranular hipidiomórfica média, caracterizada por cristais equidimensionais de feldspato potássico, plagioclásio e quartzo, com dimensões entre $0,5 \mathrm{a} 3 \mathrm{~mm}$, espaços intersticiais preenchidos por biotita, muscovita, titanita e minerais opacos. Apresenta uma incipiente foliação caracterizada pela orientação dimensional dos cristais de feldspato potássico e biotita e pelo alongamento deformacional do quartzo. Também apresenta foliação tectônica definida por recristalização do quartzo e biotita. Caracteriza-se por uma rocha tipicamente de natureza ígnea plutônica, com análise modal (vol\%) acusando 40-45\% de feldspato potássico (ortoclásio), 15-20\% de augita, 10-15\% de plagioclásio (campo do oligoclásio), 20-25\% de quartzo (deformado e caracterizado pela extinção ondulante), 1-2\% de biotita, 1-2\% de minerais opacos, além de traços de muscovita e titanita. Não há indícios de microdescontinuidades e a alteração intempérica se faz presente, principalmente, nos grãos de ortoclásio, com produção de illita. Indícios de alterações metamórficas são evidenciados em biotita que produz muscovita, titanita e minerais opacos. Pelos parâmetros de Le Maitre [20] a rocha corresponde petrograficamente a um sienogranito. O aspecto textural da rocha metamórfica (sienogranito proto-milonítico) é devido ao fato de ter sido coletado perto de uma zona de fraturas tectônica (Figura 5).

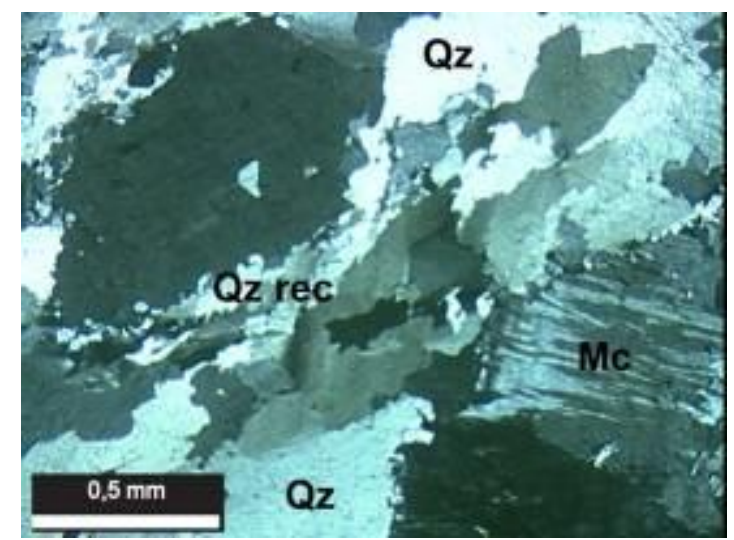

Figura 5: Rocha IV: sienogranito proto-milonítico - cristais de quartzo (Qz) deformado (estirados e com extinção ondulante) e quartzo recristalizado (Qz rec), com feldspatos micropertíticos (Mc) (LP, com nicois cruzados).

\subsection{Reatividade álcali-agregado}

A Tabela 2 e a Figura 6 apresentam os resultados dos ensaios de reatividade álcali-agregado das amostras analisadas pelo método acelerado das barras.

Tabela 2: Expansão média dos agregados determinada no ensaio de reatividade álcali-agregado.

\begin{tabular}{l|l|l|l|l|l|l|l|c}
\hline \multirow{2}{*}{ AGREGADO } & \multicolumn{6}{l}{ EXPANSÃO MÉDIA (\%) } \\
\cline { 2 - 10 } & $\mathbf{5}$ dias & $\mathbf{8}$ dias & $\mathbf{1 2}$ dias & $\mathbf{1 6}$ dias & $\mathbf{1 9}$ dias & $\mathbf{2 3}$ dias & $\mathbf{2 6}$ dias & $\mathbf{3 0}$ dias \\
\hline I & 0,00 & 0,01 & 0,04 & 0,18 & 0,25 & 0,33 & 0,36 & 0,43 \\
\hline II & 0,03 & 0,06 & 0,17 & 0,23 & 0,28 & 0,31 & 0,33 & 0,36 \\
\hline III & 0,01 & 0,03 & 0,03 & 0,05 & 0,06 & 0,09 & 0,12 & 0,11 \\
\hline IV & 0,02 & 0,01 & 0,04 & 0,10 & 0,11 & 0,11 & 0,11 & 0,11 \\
\hline
\end{tabular}




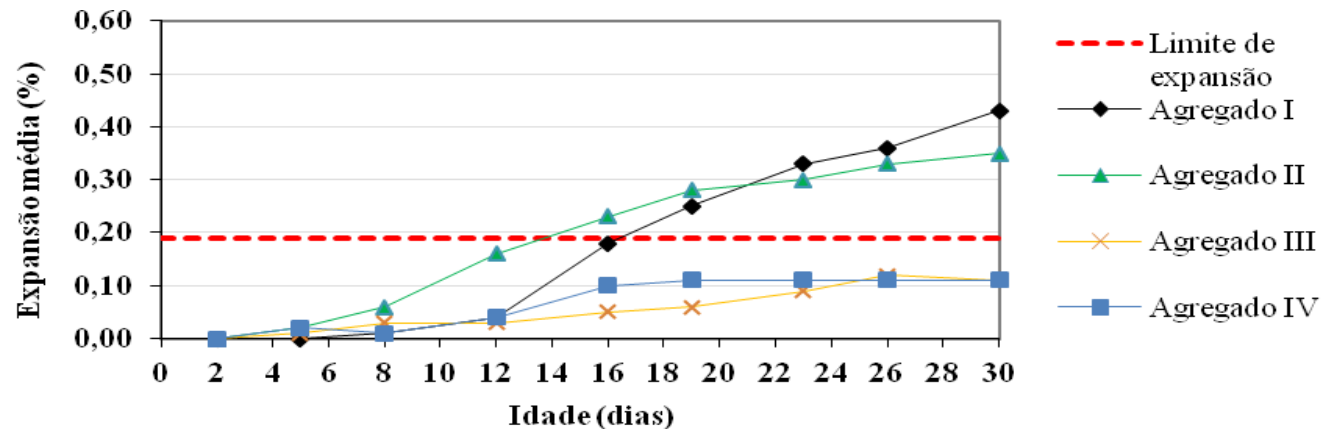

Figura 6: Evolução da expansão média dos agregados analisados.

\section{DISCUSSÃO}

Os resultados apresentados na Figura 6 indicam que os agregados provenientes de rochas ígneas vulcânicas (agregados I e II) apresentam expansão aos 30 dias de idade superior ao limite de $0,19 \%$ estabelecido na NBR 15577-1 [26] como o valor de expansão a partir do qual a rocha pode ser classificada como potencialmente deletéria em relação ao fenômeno da reação álcali-agregado. Salienta-se que mesmo com expansões acima do limite recomendado pela NBR 15577-1 [26], as barras de argamassa não apresentaram fissuração e exsudação de gel ao final do ensaio. Por outro lado, os resultados dos ensaios evidenciaram que agregados obtidos de rochas ígneas plutônicas (agregados III e IV) apresentam expansão inferior a 0,19\%, sendo consideradas potencialmente inócuas.

Embora ambas as rochas vulcânicas (agregados I e II) tenham sido identificadas como potencialmente deletérias pelo método acelerado das barras, o basalto identificado como agregado I apresentou expansão no final do ensaio aproximadamente $19 \%$ superior ao basalto identificado como agregado II, ainda que a expansão determinada até o $19^{\circ}$ dia de ensaio tenha sido menor do que para o agregado II, conforme pode ser observado na Figura 6.

A natureza geológica da cristalização dos basaltos (agregados I e II), como evidenciado pelas texturas e mineralogia, mostra que o agregado I é composto por uma matriz de grão fino com 12-15\% de vidro vulcânico (massa vitrofírica preta - Figura 2a) que induziu a uma maior taxa de resfriamento da lava durante a sua cristalização. Sabe-se que o vidro vulcânico contém criptocristais compostos de quartzo e feldspatos (tipos Mm e Mic) e minerais de argila (tipo Ma) [12], apenas visíveis em microscopia eletrônica, que são chamados de mesóstase. O agregado II, apesar de ter um maior valor de expansão do que o padrão normativo é, possivelmente, menos reativo do que o agregado I, uma vez que não há vidro em sua matriz. Provavelmente, os altos valores de expansão apresentados pelo agregado II podem estar relacionados ao seu grau de intemperismo.

No estudo realizado por TIECHER et al. [12] foi identificado que os grãos de quartzo da mesóstase são os principais responsáveis pela dissolução de sílica quando uma rocha vulcânica alcalina, como o basalto, está em contato com uma solução alcalina. No entanto, os autores salientam que resultados potencialmente reativos de rochas basálticas, obtidos de ensaios acelerados, contradizem o comportamento de estruturas com concreto produzido com rochas basálticas, visto não ser observada reação álcali-agregado em concretos com essas rochas. E apontam, ainda, que a quantidade de quartzo nos basaltos não é suficientemente significativa para promover a RAA em situações reais, visto que os ensaios de expansão acelerados exigem condições muito agressivas (alta alcalinidade e temperatura), o que provoca a rápida dissolução do quartzo microcristalino da mesóstase.

Os agregados III e IV mostraram valores de expansão abaixo dos estabelecidos pelo padrão normativo e, portanto, são consideradas rochas inócuas (não reativas) em relação à reação álcali-agregado. De acordo com a sua natureza geológica, esses litótipos não formam vidro vulcânico na cristalização devido à sua ocorrência no interior dos pacotes vulcânicos (agregado III) ou em grandes profundidades (aproximadamente seis quilômetros), dentro da crosta terrestre (agregado IV), bem como a suas condições de taxa de cristalização bastante lentas. No entanto, a petrografia de granito mostrou alguns grãos de quartzo, típicos dos processos de deformação, pela extinção ondulante, indicando um metamorfismo incipiente. Possivelmente, o quartzo deformado proveniente de processos metamórficos constitui um dos fatores desencadeantes de uma reação álcali-agregado. Essa deformação, porém, no caso do agregado IV, não foi suficiente para afetar as condições reológicas da rocha, que podem ser vistas pela curva de evolução de expansão semelhante ao agregado III, que não contém quartzo deformado (Figura 6). 
RAMOS et al. [13], ao avaliarem a reatividade potencial de treze rochas graníticas através de caracterização petrográfica e ensaios de expansão, concluíram que a análise petrográfica deve preceder os ensaios de expansão para identificar a presença, ou não, de fases minerais potencialmente reativas nos agregados. Os autores verificaram que o teor de quartzo microcristalino apresentou melhor correlação com os resultados de expansão obtidos nos ensaios de prismas de concreto do que nos ensaios acelerados com barras de argamassa.

A Tabela 3 apresenta a análise de variância realizada a partir dos resultados de reatividade potencial dos agregados analisados, a fim de verificar a influência do tipo de agregado na expansão. A Figura 7 apresenta os valores médios da expansão final dos agregados analisados, aos 30 dias de ensaio.

Tabela 3: Análise de variância.

\begin{tabular}{l|l|l|l|l|l|l}
\hline FONTE DA VARIAÇÃO & SQ & GL & MQ & F & VALOR P & F CRÍTICO \\
\hline Entre grupos & 0,24429 & 3 & 0,08143 & 72,383 & $3,87 \mathrm{E}-06$ & 4,066 \\
\hline Dentro dos grupos & 0,009 & 8 & 0,00113 & & & \\
\hline Total & 0,25329 & 11 & & & & \\
\hline
\end{tabular}

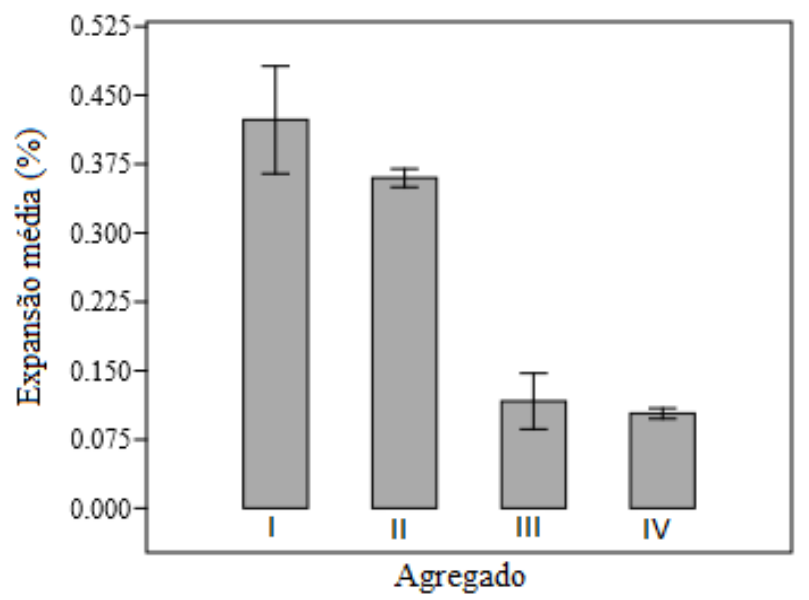

Figura 7: Expansão média, aos 30 dias de ensaio.

Conforme a análise de variância, como o valor-P é menor do que 0,05 o tipo de agregado apresenta influência significativa na expansão. A Tabela 4 apresenta o teste de Tukey, para identificação de quais tipos de agregados diferem entre si.

Tabela 4: Teste de Tukey.

\begin{tabular}{l|l|l|l|l}
\hline AGREGADO & I & II & III & IV \\
\hline I & - & 0,1742 & 0,0002354 & 0,0002334 \\
\hline II & 3,271 & - & 0,0002909 & 0,0002665 \\
\hline III & 15,84 & 12,57 & - & 0,9599 \\
\hline IV & 16,52 & 13,25 & 0,6885 & - \\
\hline
\end{tabular}

Os resultados do teste de Tukey mostram que a expansão dos agregados I e II não diferem significativamente entre si, assim como os agregados III e IV não apresentam expansões significativamente diferentes. No entanto a expansão dos agregados I e II diferem significativamente dos agregados II e IV. Esses resultados estão de acordo com as observações da análise petrográfica.

\section{CONCLUSÕES}

O presente trabalho teve como foco a caracterização petrográfica de quatro agregados e a reatividade álcaliagregado em concreto. As principais conclusões são descritas a seguir. 
- O agregado I (rocha basáltica) foi o mais reativo em relação à reação álcali-agregado (expansão média em torno de $0,43 \%$ ), classificado como potencialmente reativo. É composto por uma porcentagem significativa de vidro vulcânico e mesóstase de tipo Ma em sua matriz (presença de celadonita), além de calcita na área vesicular, um mineral que também pode estimular a reação;

- O agregado II (rocha basáltica) apresentou a segunda maior reatividade álcali-agregado (expansão média de $0,36 \%$ ), sendo também classificado como potencialmente reativo, segundo o padrão normativo. Sua menor expansividade em comparação com o agregado I pode ser devido à ausência de vidro vulcânico em sua matriz;

- O agregado III (olivina-gabro) não apresentou reatividade potencial, sendo uma rocha potencialmente inócua em relação à reação álcali-agregado;

- O agregado IV (sienogranito proto-milonítico) também não apresentou reatividade potencial, sendo também uma rocha potencialmente inócua em relação a uma reação álcali-agregado. A presença de quartzo deformado é devido a um processo metamórfico incipiente que não impede o uso desta rocha como agregado na produção de concreto.

Assim, segundo os resultados do presente trabalho, recomenda-se evitar o uso de rochas com áreas de vesículas-amígdaloides de derrames vulcânicos como agregado para concreto de cimento Portland, uma vez que a presença de minerais como calcita e argila (tipo celadonita), nas porções encontradas pode criar condições favoráveis para a reação álcali-agregado. Estudos adicionais estão em andamento, a fim de avaliar a reatividade potencial dos mesmos agregados analisados no presente trabalho, através de métodos não acelerados. A utilização de rochas potencialmente reativas na produção de concretos de cimento Portland fica condicionada ao emprego de adições minerais mitigatórias da reação álcali-agregado.

\section{AGRADECIMENTOS}

Os autores agradecem ao CNPq - Conselho Nacional de Desenvolvimento Científico e Tecnológico, pelo apoio financeiro, e à CIENTEC - Fundação de Ciência e Tecnologia, pela britagem e preparação dos agregados.

\section{BIBLIOGRAFIA}

[1] MEHTA, P.K., MONTEIRO, P.J.M., Concreto: microestrutura, propriedades e materiais, 2 ed., São Paulo, IBRACON, 2014.

[2] BICZÓK, I., Corrosión y protección del hormigón, 6 ed., Bilbao, Urmo, 1972.

[3] HOBBS, D. W., Alkali silica reaction in concrete, London, Thomas Telford, 1988.

[4] CARLES-GIBERGUES, A., HORNAIN, H., “A durabilidade do concreto frente às reações expansivas de origem endógena", In: Ollivier, J-P., Vichot, A. (eds), Durabilidade do concreto: bases científicas para a formulação de concretos duráveis de acordo com o ambiente , Tradução: Cascudo, O., Carasek, H., 1 ed., capítulo 10, São Paulo, IBRACON, 2014.

[5] PECCHIO, M., KIHARA, Y., BATTAGIN, A., et al., "Produtos da reação álcali-silicato em concretos de edificações da região do grande Recife", In: RAA 2006 - II Simpósio sobre reação álcali-agregado em estruturas de concreto, Rio de Janeiro, Setembro 2006.

[6] SILVA, P. N., Reação álcali-agregado nas usinas hidroelétricas do complexo Paulo Afonso/CHESF: influência da reação nas propriedades do concreto, Dissertação de M.Sc., Escola Politécnica/USP, São Paulo, SP, Brasil, 2007.

[7] TIECHER, F., DAL MOLIN, D.C.C., "Método de ensaio da ASTM C 1260: Avaliação das idades prescritas para o estabelecimento da potencialidade reativa dos agregados", In: RAA 2006 - II Simpósio sobre reação álcali-agregado em estruturas de concreto, Rio de Janeiro, Setembro 2006.

[8] VALDUGA, L., Reação álcali-agregado: mapeamento de agregados reativos do estado de São Paulo, Dissertação de M.Sc., Faculdade de Engenharia Civil/UNICAMP, Campinas, SP, Brasil, 2002.

[9] PAULON, V.A., "Reações álcali-agregado no concreto", Dissertação de M.Sc., Escola Politécnica/USP, São Paulo, SP, Brasil, 1981.

[10] WAKISAKA, Y., “Alcali-silica reactivity of japonese rocks”, Engineering Geology, v. 56, pp. 211-221, 2000. 
[11] CARDOSO, A.S., HASPARYK, N.P., DÓREA, S.C.L. "Reações álcali-agregado: potencialidade reativa dos agregados utilizados em concretos no estado de Sergipe", In: $51^{\circ}$ Congresso Brasileiro do Concreto, 16 pp., Curitiba, Setembro, 2009.

[12] TIECHER, F., DAL MOLIN, D.C.C., GOMES, M.E.B., HASPARIK, N.P., MONTEIRO, P.J.M. "Influence of mesostasis in volcanic rocks on the alkali-aggregate reaction", Cement and Concrete Composites, v. 34, n. 10, pp. 1130-1140, 2012.

[13] RAMOS, V., FERNANDES, I., SILVA, A.S., et al. "Assesment of the potencial reactivity of granitic rocks - Petrography", Cement and Concrete Research, v. 86, pp. 63-77, 2016.

[14] HASPARIK, N.P., Investigação de concretos afetados pela reação álcali-agregado: efeito da casca de arroz e da sílica ativa, Dissertação de M.Sc., Escola de Engenharia Civil/UFG, Goiânia, SP, Brasil, 1999.

[15] SILVEIRA, A.A., Contribuição ao estudo do efeito da incorporação de coinza de casca de arroz em concretos submetidos à reação álcali-agregado, Tese de D.Sc., Escola de Engenharia/PPGEC/UFRGS, Porto Alegre, RS, Brasil, 2007.

[16] SILVA, C.M., Estudo da potencialidade de compostos a base de silanos no combate da reação álcaliagregado, Dissertação de M.Sc., Escola de Engenharia/PPGEC/UFRGS, Porto Alegre, RS, Brasil, 2009.

[17] ROSTAMI, M., BEHFARNIA, K. "The effect of silica fume on durability activated slag concrete", Construction and Building Materials, v. 134, pp. 262-268, 2017.

[18] RAJABIPOUR F., GIANNINI, E., DUNANT, C., et al., "Alkali-silica reaction: Current understanding of the reaction mechanisms and the knowlwdge gaps", Cement and Concrete Research, v. 76, pp. 130-146, 2015.

[19] ALMEIDA F.F.M., HASSUI, Y., BRITO-NEVES, B.B. de. "Brazilian Structural Provinces: an Introduction”, Earth Sciences Review, v. 17, n. 1-2, pp. 1-129, 1981.

[20] LE MAITRE, R.W., A classification of igneous rocks and glossary of terms: recommendations of the International Union of Geological Sciences - subcomission on the systematic of igneous rocks, Oxford, Blackwell Scientific Publications, 1989.

[21] SENFF, L., HOTZA, D., LUCAS, S., et al., "Effect of nano-SiO ${ }_{2}$ and nano- $\mathrm{TiO}_{2}$ addition on the rheological behavior and the hardened properties of cement mortars", Materials Science and Engineering. A, Structural Materials:properties, microstructure and processing, v. 532, pp. 354-361, 2012.

[22] ASSOCIAÇÃO BRASILEIRA DE NORMAS TÉCNICAS. NBR NM 53: Agregado graúdo - determinação da massa específica, massa específica aparente e absorção de água. Rio de Janeiro, 2009.

[23] ASSOCIAÇÃO BRASILEIRA DE NORMAS TÉCNICAS. NBR NM 23: Cimento Portland e outros materiais em pó - determinação da massa específica. Rio de Janeiro, 2001.

[24] ASSOCIAÇÃO BRASILEIRA DE NORMAS TÉCNICAS. NBR NM 76: Cimento Portland - determinação da finura pelo método de permeabilidade ao ar (Método de Blaine). Rio de Janeiro, 1998.

[25] ASSOCIAÇÃO BRASILEIRA DE NORMAS TÉCNICAS. NBR 15845: Rochas para revestimento análise petrográfica - método de ensaio. Rio de Janeiro, 2010.

[26] ASSOCIAÇÃO BRASILEIRA DE NORMAS TÉCNICAS. NBR 15577-1: Agregados - Reatividade álcali-agregado - parte 1: guia para avaliação da reatividade potencial e medidas preventivas para uso de agregados em concreto. Rio de Janeiro, 2008.

[27] ASSOCIAÇÃO BRASILEIRA DE NORMAS TÉCNICAS. NBR 15577-4: Agregados - Reatividade álcali-agregado - parte 4: determinação da expansão em barras de argamassa pelo método acelerado. Rio de Janeiro, 2008.

[28] ASSOCIAÇÃO BRASILEIRA DE NORMAS TÉCNICAS. NBR 5733: Cimento Portland de alta resistência inicial. Rio de Janeiro, 1991. 